\title{
Clinical Profile and Outcome of Mechanically Ventilated Neonates in a Tertiary Level Hospital
}

\author{
Shrestha $\mathrm{P}^{1}$, Basnet $\mathrm{S}^{2}$, Shrestha $\mathrm{L}^{3}$
}

\begin{abstract}
Introduction: Many sick neonates admitted to neonatal intensive care unit (NICU) require mechanical ventilation but it is associated with various complications and the outcome of neonates is unpredictable. This study aims to identify the indications for mechanical ventilation, complications, co-morbid conditions and outcome of those neonates in terms of survival. Materials and Methods: Retrospective observational study of all neonates who underwent mechanical ventilation from 1 January 2014 to 31 December 2014 in NICU, Tribhuvan University Teaching Hospital. Medical records of the patients were retrieved from hospital record section to collect the relevant data. Results: One-third of admitted neonates in NICU required mechanical ventilation (MV). Commonest indication was severe respiratory distress (70\%) followed by perinatal asphyxia (12\%) and recurrent apnea (8\%). Disease pattern were sepsis (37.2\%), RDS of prematurity (17.6\%), perinatal asphyxia (11.7\%), meconium aspiration syndrome (9.8\%), apnea of prematurity (7.8\%) and congenital pneumonia (4\%). Hospital acquired sepsis was a major complication occurring in $47 \%$ patients on mechanical ventilation. Survival rate among neonates on $\mathrm{MV}$ was 33\%. Survival was better with increasing birth weight and gestational age. Survival was $100 \%$ in congenital pneumonia, $50 \%$ in perinatal asphyxia, $50 \%$ in recurrent apnea, $26 \%$ in sepsis, $20 \%$ in MAS and $0 \%$ in RDS of prematurity. Conclusion: Survival rate of neonates on mechanical ventilation in NICU was 33\%. Sepsis was a major problem in NICU, which must be addressed to improve outcome.
\end{abstract}

Key words: Mechanical ventilation, RDS of prematurity, sepsis,

\section{Introduction}

T he fall in neonatal mortality rate in Nepal has been steady, and has been documented by WHO as 24.4 per 1000 live births in $2012^{1}$. Sustainable Development Goals target to reduce neonatal mortality to atleast as low as 12 per 1000 live births by $2030^{2}$. Improving intensive care facilities for the neonates in the country could be one of the effective interventions to achieve this. Efforts must be towards improving and sustaining the neonatal intensive care units at tertiary care centers as well as to establish more level II and III care facilities in the district hospitals and other centers at
'Dr. Prabina Shrestha, MBBS, MD, Teaching Assistant, ${ }^{2}$ Dr. Srijana Basnet, MBBS, MD, Associate Professor, ${ }^{3}$ Dr. Laxman Shrestha, Professor and HoD. All from the Department of Paediatrics, Tribhuvan University Teaching Hospital (TUTH), Institute of Medicine (IoM), Maharajgunj, Kathmandu, Nepal.

\section{Address for correspondence:}

Dr. Prabina Shrestha

Teaching Assistant, Department of Paediatrics,

Tribhuvan University Teaching Hospital,

Kathmandu, Nepal.

E-mail: prabinas@gmail.com

Tel: +9779851130785

\section{How to cite}

Shrestha P, Basnet S, Shrestha L. Clinical Profile and Outcome of Mechanically Ventilated Neonates in a Tertiary Level Hospital. J Nepal Paediatr Soc 2015;35(3):218-223.

doi: http://dx.doi.org/10.3126/jnps.v35i3.13328

This work is licensed under a Creative Commons Attribution 3.0 License.

\section{(c) (7)}

the periphery. Mechanical ventilation is an essential part of the neonatal intensive care facility. However, the effective functioning of NICU, depends not just on expensive high technology equipments and complex infrastructure, but also on medical and nursing expertise and multidisciplinary support from laboratory, radiology, physiotherapy, etc.

Currently, there are several medical colleges and private hospitals providing intensive care for neonates in Kathmandu. Tribhuvan University Teaching Hospital (TUTH) being a tertiary care referral center receives many obstetric referrals for maternal or fetal conditions and neonate referrals from all over the country with the expectation of better neonatal outcome. 
Many of these admitted newborns are critically sick and require mechanical ventilation. The survival of sick neonates have improved significantly with the widespread use of mechanical ventilation in NICUs ${ }^{3,4}$. Several studies show that weight and gestational age are major determinants of neonatal mortality ${ }^{4,5}$. It is also related with severity of illness at admission, complications related to ventilator techniques and strategies and occurrence of co-morbid conditions like sepsis, coagulopathy, multiorgan dysfunction, congenital malformations etc ${ }^{5,6}$.

There is paucity of data about outcome of neonates undergoing mechanical ventilation and its various complications in our country. These parameters would be useful to evaluate the functioning and outcome of NICUs as well as to prognosticate the admitted newborns. The present study aims to identify the common indications for mechanical ventilation, possible correlation of underlying diseases with survival of neonates and complications occurring during mechanical ventilation.

\section{Material and Methods}

This was a retrospective observational study of all neonates who underwent mechanical ventilation from 1st January to 31st December, 2014 in NICU, TUTH. Medical records of the patients were retrieved from hospital record section to collect the data, regarding gestational age, birth weight, mode of delivery, apgar scores, maternal medical issues, admitting diagnosis, indication of mechanical ventilation, duration of mechanical ventilation and outcome. Occurrence of any complications during ventilation like pneumothorax, hospital acquired sepsis, ventilator associated pneumonia, DIC, pulmonary haemorrhage, and other co-morbid conditions like shock, acute kidney injury, sepsis, intraventricular haemorrhage, necrotizing enterocolitis were recorded. All neonates were grouped into two - "survivors" and "non-survivors". Birth weight and gestational age was sub-grouped into 4 and 5 groups respectively and its relation to survival rate was analyzed using chi square test. Association of various complications with outcome was analysed by univariate analysis and odds ratio was calculated. P-value less than 0.05 was considered statistically significant. The data was entered and analyzed using SPSS 16.

\section{Results}

There were 174 babies admitted in NICU in January-December 2014. Out of them, 56 were ventilated, constituting $32 \%$ of the admitted neonates in NICU. Among them, the detail records of only 51 could be retrieved, so were included in the study. There were 17 survivors (33.3\%) and 34 non-survivors (66.7\%). Nine babies who were discontinued from medical care when they became critically ill were also included in the "non- survivor" group. There were 34 males and 17 females. Majorities (94\%) were inborn babies, among which 19 babies were born by vaginal delivery, one underwent vacuum application and 31 were delivered by caesarian section. Indications for caesarian section were maternal eclampsia, severe pregnancy induced hypertension, antepartum hemorrhage, maternal cardiac disease, oligohydramnios, fetal distress, meconium stained liquor and premature rupture of membrane. Antenatal steroid was received by 13 mothers.

There were three babies weighing less than 1000 grams, 15 babies between 1000 - 1499 grams, 11 between 1500 - 2499 grams and 22 babies weighing more than 2500 grams. None of the neonates weighing less than 1000 grams survived, half of those weighing more than 1500 grams survived. There were 23 (45\%) preterm babies and 28 (55\%) term babies. None of the neonates less than 32 weeks gestation survived. Survival rate gradually increased with increasing gestational age, $26.6 \%$ in $32-33$ weeks, $33.3 \%$ in late preterm (34-37 weeks) and 50\% in term(>37 weeks). Table 1 shows particulars of the neonates in relation to survival rate. The survival rate was significantly related to birth weight of neonates ( $p$-value=0.019) and gestational age of neonates ( $p$-value 0.039 ).

The most common indication for mechanical ventilation was severe respiratory distress (gasping respiration / respiratory distress score $>5$ / SpO2 <80\% with oxygen via CPAP) seen in 36 neonates (70\%) while it was birth asphyxia in 6 neonates (12\%). Other indications were recurrent apnea in $4(8 \%)$, recurrent seizures in 2 (4\%), diaphragmatic hernia in 1 (2\%) and failure to extubate following a major surgery in 2 neonates (4\%).

The disease pattern in mechanically ventilated neonates is shown is Table 3 with respective survival outcomes. Most common was sepsis in 19 patients (37.2\%) including pneumonia, meningitis, necrotizing enterocolitis. Respiratory distress syndrome of prematurity was present in 9 (RDS 17.6\%), meconium aspiration syndrome in 5 (MAS 9.8\%), birth asphyxia in $6(11.7 \%)$, apnea of prematurity in $4(7.8 \%)$, congenital pneumonia in two, congenital heart disease in one, pneumomediastinum in two, congenital diaphragmatic hernia in one and for post operative surgical care in two patients. 
Time of initiation of ventilation was within 24 hours of admission in $28 \%$ and after stay of 7 days in NICU in $20 \%$. The mean duration of mechanical ventilation was 118 hours (Range 1-360 hours).

None of the neonates with RDS of prematurity survived. Survival rate was $25.3 \%$ in sepsis, $20 \%$ in MAS, $50 \%$ in birth asphyxia and $50 \%$ in apnea of prematurity group. Neonates with RDS of prematurity were started on bubble CPAP, and those who did not improve were administered surfactant as rescue therapy. Surfactant was expensive and not readily available. It was administered by INSURE technique following which neonates were kept under bubble CPAP. Only those who had persistent distress on bubble CPAP or developed some complications were mechanically ventilated ${ }^{7,8,9}$. In this study, 8 preterm neonates weighing 1250 2250 grams (mean 1650 grams) of gestation 26-34 weeks (mean 30 weeks) were administered surfactant. Out of eight, four needed mechanical ventilation soon after administration, later developed sepsis and died. The other four neonates improved on bubble CPAP after surfactant administration, but later during the course of hospital stay developed sepsis and required ventilation and subsequently succumbed. The causes of death were intraventricular hemorrhage (3), septic shock (4), necrotizing enterocolitis (1) and pulmonary hemorrhage (1).
Several co-morbid conditions like sepsis, shock, acute kidney injury, disseminated intravascular coagulation, metabolic acidosis, dyselectrolytemia were seen. Table 3 demonstrates the occurrence of various complications and their association with outcome on univariate analysis.

Hospital acquired sepsis was a major complication occurring in $47 \%$ patients on mechanical ventilation, manifested as ventilator associated pneumonia, meningitis, necrotizing enterocolitis and septic ileus. There were 16 blood culture positive cases whose antibiotic sensitivity pattern as shown in Table 5 . There was an outbreak of Klebsiella pneumoniae, isolated in six patients. Only $18.7 \%$ of blood culture positive neonates survived.

Acute kidney injury was present in $24 \%$ of patients, associated with poor outcome (25\%) although it was not statistically significant. Two patients underwent peritoneal dialysis but both succumbed. Disseminated intravascular coagulation and pulmonary haemorrhage was present in $20 \%$ and $12 \%$ respectively. Pneumothorax was present in four patients, one was associated with pneumomediastinum before undergoing mechanical ventilation.

Table 1: Profile of ventilated neonates and relation to mortality

\begin{tabular}{|c|c|c|c|c|}
\hline S No. & Parameters & Total no of neonates & No of survivors (Percentage of survival) & $p$-value \\
\hline \multirow{5}{*}{1} & \multicolumn{3}{|l|}{ Birth weight groups } & \multirow{5}{*}{0.019} \\
\hline & $<1000$ grams & 3 & $0(0)$ & \\
\hline & 1000-1499 grams & 15 & $1(6.7 \%)$ & \\
\hline & 1500-2499 grams & 11 & $6(54.4 \%)$ & \\
\hline & 2500 grams or more & 22 & $10(45.5 \%)$ & \\
\hline \multirow{6}{*}{2} & \multicolumn{3}{|l|}{ Gestational age groups } & \multirow{6}{*}{0.039} \\
\hline & $<28$ weks & 3 & $0(0)$ & \\
\hline & 28-31weeks & 10 & $0(0)$ & \\
\hline & 32-33weeks & 7 & $2(26.6 \%)$ & \\
\hline & 34-37weeks & 3 & $1(33.3 \%)$ & \\
\hline & $>37$ weeks & 28 & $14(50 \%)$ & \\
\hline
\end{tabular}

Table 2: Indications for initiation of mechanical ventilation

\begin{tabular}{|c|l|c|}
\hline S No & Indications for ventilation & Number of patients (percentage \%) \\
\hline 1 & Severe respiratory distress & $36(70 \%)$ \\
\hline 2 & Perinatal asphyxia & $6(12 \%)$ \\
\hline 3 & Recurrent apnea & $4(8 \%)$ \\
\hline 4 & Recurrent seizures & $2(4 \%)$ \\
\hline 5 & Diaphragmatic hernia & $1(2 \%)$ \\
\hline 6 & During surgery & $2(4 \%)$ \\
\hline 7 & Total & $\mathbf{5 1 ( 1 0 0 \% )}$ \\
\hline
\end{tabular}


Table 3: Disease Pattern of mechanically ventilated neonates and its outcome.

\begin{tabular}{|c|l|c|c|}
\hline S. No & $\begin{array}{l}\text { Disease Pattern of mechanically ventilated } \\
\text { neonates }\end{array}$ & $\begin{array}{c}\text { Total neonates ventilated } \\
\text { (percentage out of total) }\end{array}$ & $\begin{array}{c}\text { Number of survivors } \\
\text { (Percentage) }\end{array}$ \\
\hline 1 & Sepsis & $19(37.2 \%)$ & $5(26.3 \%)$ \\
\hline 2 & RDS of prematurity & $9(17.6 \%)$ & 0 \\
\hline 3 & Meconium aspiration syndrome & $5(9.8 \%)$ & $1(20 \%)$ \\
\hline 4 & Perinatal asphyxia & $6(11.7 \%)$ & $3(50 \%)$ \\
\hline 5 & Apnea of Prematurity & $4(7.8 \%)$ & $2(50 \%)$ \\
\hline 6 & Congenital Pneumonia & 2 & 2 \\
\hline 7 & Congenital heart disease & 1 & 1 \\
\hline 8 & Pneumomediastinum & 2 & 0 \\
\hline 9 & Diaphragmatic hernia & 1 & 2 \\
\hline 10 & During surgery (duodeno-duodenostomy) & 2 & 1 \\
\hline
\end{tabular}

Table 4: Univariate analysis showing association of these parameters with mortality

\begin{tabular}{|c|l|c|c|c|c|c|}
\hline S No & Complications & $\begin{array}{c}\text { Number of patients with } \\
\text { complications (\%) }\end{array}$ & $\begin{array}{c}\text { Survivors } \\
\text { (\%) }\end{array}$ & $\begin{array}{c}\text { Odds } \\
\text { ratio }\end{array}$ & $\begin{array}{c}\text { 95\% Confidence } \\
\text { interval }\end{array}$ & p-value \\
\hline 1 & Shock & $41(80)$ & $19(46.3)$ & 4.4 & $1.25-15.48$ & 0.017 \\
\hline 2 & Hospital acquired sepsis & $24(47)$ & $9(37.5)$ & 0.55 & $0.17-1.80$ & 0.244 \\
\hline 3 & Acute Kidney Injury & $12(24)$ & $3(25)$ & 1.68 & $0.39-7.24$ & 0.484 \\
\hline & $\begin{array}{l}\text { Disseminated } \\
\text { Intravascular }\end{array}$ & $10(20)$ & $1(10)$ & 6.0 & $0.69-52.06$ & 0.073 \\
\hline 5 & loagulation & $6(12)$ & $2(33)$ & 1.29 & $0.22-7.47$ & 0.774 \\
\hline 6 & Pneumothorax & $4(8)$ & $1(25)$ & 1.55 & $0.15-16.11$ & 0.713 \\
\hline
\end{tabular}

Table 5: Sensitivity pattern of organisms isolated in Blood culture

\begin{tabular}{|c|c|c|c|c|c|}
\hline $\begin{array}{l}\text { Sr } \\
\text { No }\end{array}$ & Organisms isolated & $\begin{array}{c}\text { No of } \\
\text { patients. }\end{array}$ & Sensitive Antibiotics & Resistant Antibiotics & $\begin{array}{l}\text { Numbers } \\
\text { Survived }\end{array}$ \\
\hline 1 & $\begin{array}{l}\text { Klebsiella } \\
\text { pneumoniae }\end{array}$ & 4 & $\begin{array}{l}\text { Ciprofloxacin, Amikacin, meropenem, } \\
\text { Piperacillin-Tazobactum, Tigecycline, } \\
\text { Colistin }\end{array}$ & $\begin{array}{l}\text { Ampicillin, Amikacin, } \\
\text { Meropenem }\end{array}$ & 1 \\
\hline 2 & $\begin{array}{l}\text { Klebsiella } \\
\text { pneumoniae }\end{array}$ & 2 & $\begin{array}{l}\text { Imipenem, Tigecycline, Colistin, } \\
\text { Chloramphenicol, Polymyxin }\end{array}$ & $\begin{array}{l}\text { Ampicillin, Ciprofloxacin, } \\
\text { Meropenem, Cefepime, } \\
\text { Piperacillin-Tazobactum }\end{array}$ & 0 \\
\hline 3 & $\begin{array}{l}\text { Acinetobacter } \\
\text { baumanii }\end{array}$ & 3 & $\begin{array}{l}\text { Ciprofloxacin, Tigecycline, Colistin, } \\
\text { Polymyxin }\end{array}$ & Meropenem & 0 \\
\hline 4 & $\begin{array}{l}\text { Pseudomonas } \\
\text { aeruginosa }\end{array}$ & 1 & $\begin{array}{l}\text { Ceftazidime, Amikacin, Piperacillin- } \\
\text { Tazobactum, Cotrimoxazole }\end{array}$ & Gentamicin, Ofloxacin & 1 \\
\hline 5 & Eschereria coli & 2 & $\begin{array}{l}\text { Ciprofloxacin, Amikacin, Piperacillin- } \\
\text { Tazobactum, Colistin }\end{array}$ & Ampicillin & 0 \\
\hline 6 & $\begin{array}{l}\text { Staphylococcus } \\
\text { aureus }\end{array}$ & 1 & $\begin{array}{l}\text { Cloxacillin, Amikacin, Levofloxacin, } \\
\text { Vancomycin, Piperacillin-Tazobactum }\end{array}$ & Ampicillin & 1 \\
\hline 7 & $\begin{array}{l}\text { Coagulase negative } \\
\text { Staphylococcus }\end{array}$ & 1 & $\begin{array}{l}\text { Ampicillin, Amikacin, Ciprofloxacin, } \\
\text { Piperacillin-Tazobactum }\end{array}$ & & 0 \\
\hline 8 & Citrobacter fruendii & 1 & $\begin{array}{l}\text { Amikacin, Ciprofloxacin, Meropenem, } \\
\text { Piperacillin-Tazobactum Tigecycline }\end{array}$ & & 0 \\
\hline 9 & $\begin{array}{l}\text { Burkholderia } \\
\text { cepacia }\end{array}$ & 1 & $\begin{array}{l}\text { Amikacin, Ciprofloxacin, Meropenem, } \\
\text { Piperacillin-Tazobactum, Tigecycline }\end{array}$ & Ampicillin, Cefotaxime & 0 \\
\hline
\end{tabular}




\section{Discussion}

The survival rate of neonates on mechanical ventilation in developing countries ranges from $25 \%$ to $64 \%{ }^{10,11,12,13,14,15}$. In our study, one-third of admitted neonates required mechanical ventilation and among them one-third survived (33.3\%). Similar to data from other NICUs, in this study outcome was better with increasing birth weight and gestational age $\mathrm{e}^{10,11,12,13,14,15}$. Half of neonates in the study were preterm (51\%). Survival rate was $33.3 \%$ for $34-37$ weeks, $26.6 \%$ for 32-33 weeks and none survived below 31 weeks.

The most common indication for ventilation was respiratory distress and sepsis. Similar pattern was seen at Patan Hospital, Nepal with indication being $33 \%$ HMD and $24 \%$ severe sepsis ${ }^{14}$. The commonest reason for ventilation described was respiratory distress(63\%) in West Indies, birth asphyxia(60\%) in Paropakar Maternity and Women's Hospital, Nepal and (34\%)in BPKIHS, Nepal ${ }^{10,13,15}$. It was MAS in JIPMER ${ }^{11}$.

The disease pattern in preterm were RDS of prematurity, apnea of prematurity, sepsis and in term were perinatal asphyxia, meconium aspiration syndrome and sepsis. In this study, survival was nil in RDS of prematurity. The poor outcome of neonates on MV for RDS of prematurity were limited use of surfactant, co-existence of co-morbidities like shock, intracranial hemorrhage and occurrence of sepsis, necrotizing enterocolitis, disseminated intravascular coagulation and pulmonary hemorrhage. Survival outcome of neonates on MV for RDS varied a lot and was reported to be $0 \%$ by Gurbacharya et al, 33.3\% by Shah et al, $54 \%$ by Shrestha $S$ et al from hospitals within the country. Use of surfactant was limited due to its cost and unavailability, similar to other centres in Nepal ${ }^{13,14,15}$. Outcome of neonates with RDS of prematurity was $82.6 \%$ in Kerala by Prabha et al and the authors attributed the good outcome to universal use of surfactant ${ }^{16}$. In a study from West Indies, use of surfactant was $26 \%$ and there was no difference between neonates who received surfactant and who did not $^{10}$.

Survival of neonates with MAS was $20 \%$ in this study comparable to $25 \%$ in the study by Gurbacharya SM et al, but poorer that $60.7 \%$ in a series from JIPMER and $82 \%$ by Trotman ${ }^{10,11,13}$. Perinatal asphyxia constituted $11 \%$ of the mechanically ventilated neonates, among which survival rate was $50 \%$. Non survivors included neonates with neurological deficits who failed to improve despite treatment and/or were withdrawn from medical care by the parents. Studies show wide range of survival, $31.6 \%$ in Bangladesh, $68.2 \%$ in BPKIHS to $100 \%$ in Kerala ${ }^{12,14,16}$.

Sepsis had a grave outcome. Survival was only $26.3 \%$. Iqbal $Q$ et al had survival of $35.3 \%$, and Anantharaj A et al had $46.1 \%{ }^{11,17}$. There was an outbreak of Klebsiella pneumoniae during the study period, and was responsible for increased incidence of sepsis and mortality. The organism was isolated in blood culture of 6 neonates, out of which only one survived. Most of these organisms were sensitive to ciprofloxacin, piperacillin-tazobactum and meropenem. However, two isolated were carbapenem-resistant strains. Similar outbreaks of Klebsiella in other NICUs were described with $64 \%$ mortality by Grey J et al at Guatemala ${ }^{18}$. Saleem AF et al described the increase in incidence of multidrug resistant Klebsiella pneumonia in NICU in Pakistan ${ }^{19}$. Sepsis was also a major issue in Patan Hospital NICU where it was the most common cause for need of mechanical ventilation as well as most common cause of mortality among admitted neonates ${ }^{14}$. Khattab $A$ et al reported ventilator associated pneumonia in $55.2 \%$ neonates on mechanical ventilation ${ }^{20}$.

Septic shock, DIC, pulmonary hemorrhage, acute kidney injury, necrotizing enterocolitis, intraventricular hemorrhage and pneumothorax were associated with high mortality rates ${ }^{21,22}$. From a study in Kerala, shock was the commonest complication with $73.8 \%$ survival. They also found that DIC and pulmonary hemorrhage were predictive of mortality, the latter usually being a terminal event ${ }^{16}$. Riyas PK et al found complications in $58.8 \%$ neonates, including tube block (36\%) and air leak $(15 \%)^{6}$. Pneumothorax occurred in 4 neonates in this study, among which only one survived. Details of ventilator parameters and events during the course of ventilation like accidental extubations, re-intubations, risk factors for hospital acquired infections could not be collected which are our limitations and further prospective studies are warranted.

\section{Conclusions}

One third of babies admitted to NICU required mechanical ventilation and the most common indication was severe respiratory distress. The disease pattern in preterm were RDS of prematurity, apnea of prematurity, sepsis and in term were perinatal asphyxia, meconium aspiration syndrome and sepsis. The survival rate of ventilated neonates was 33.3\%. The higher gestational age and birth weight was significantly associated with better outcome. Hospital acquired sepsis was a major complication, resulting in most of the deaths with multi-organ dysfunction. The 
bacteria isolated were multidrug resistant. Effective measures for prevention and management of sepsis could improve the outcome of neonates in NICU.

Acknowledgements: We are thankful to statistician Dr. Amod Kumar Poudyal and all the residents and staff of NICU.

Funding: Nil

Conflict of Interest: None

Permission from IRB: Yes

\section{References}

1. UNICEF/WHO/The World Bank/UN Pop Div. Levels and Trends in Child Mortality. Report 2013.

2. United Nations. Transforming our world: the 2030 agenda for sustainable development. A/RES/70/1.

3. Richardson DK, Gray JE, Gortmaker SL, Goldmann DA, Parsley DM, McCormick MC. Declining severity adjusted mortality: evidence of improving neonatal intensive care. Pediatrics 1998;102:89399.

4. KeszlerM.Stateoftheartinconventionalmechanical ventilation. J Perinatol 2009;29(4):262-275.

5. Kambarami R, Chidede O, Chirisa M. Neonatal intensive care in a developing country: outcome and factors associated with mortality. Cent Afr J Med 2000;46:205-7.

6. Riyas PK, Vijayakumar KM, Kulkarni ML. Neonatal mechanical ventilation. Indian J Pediatr 2003;70:537-40.

7. Davis PG, Morley CJ, Owen LS. Non-invasive respiratory support of preterm neonates with respiratory distress: continuous positive airway pressure and nasal intermittent positive pressure ventilation. Semin Fetal Neonatal Med 2009;14(1):14-20.

8. Rezzonico et al. Impact of the systematic introduction of low-cost bubble nasal CPAP in a NICU of a developing country: a prospective pre- and post-intervention study. BMC Pediatrics 2015;15:26.

9. Vidyasagar D, Velaphi S, Vhat VB. Surfactant replacement therapy in developing countries. Neonatology 2011;99:355-66.

10. H Trotman. The Neonatal Intensive Care Unit at the University Hospital of the West Indies- The first few years' experience. West Indian Med J 2006;55(2):75.

11. Anantharaj A, Bhat BV. Outcome of neonates requiring assisted ventilation. Turkish $J$ Pediatr 2011;53:547-53.

12. Hossain MM, Shirin M, Mamun MA, Hasan MN, Sahidullah M. predictors of mortality in ventilated neonates in Intensive care unit. Bangladesh J Child Health 2009;33(3):77-82.

13. Gurubacharya SM, Aryal DR, Misra M, Gurung R. Short-Term Outcome of Mechanical Ventilation in Neonates. J Nepal Paedtr Soc 2011;31(1):35-38.

14. Shrestha S, Karki U. Indicators of admission and outcome on a newly established neonatal intensive care unit in a developing country (Nepal). Nepal Med Coll J 2012;14(1):64-67.

15. Shah et al. Mechanical Ventilation in Neonates: Experience at a tertiary care centre in Eastern Nepal. BJMMR 2015;5(1):75-80.

16. Prabha PCN, Georg RT, Francis F. Profile and outcomes of neonates requiring ventilation: The Kerala Experience. Curr Pediatr Res 2014;18(2):5762.

17. Qazi Iqbal, Mir M. Younus, Asif Ahmed, Ikhlas Ahmad, Javed Iqbal, Bashir A. Charoo, and S Wajid Ali. Neonatal mechanical ventilation: Indications and outcome. Indian J Crit Care Med 2015;19(9):523-27.

18. Gray J et al. An outbreak of Klebsiella pneumonia late-onset sepsis in a neonatal intensive care unit in Guatemala. American J Infect Control 2012;40(6):516-52.

19. Saleem AF, Qamar FN, Shahzad H, Qadir M, Zaidi AK. Trends in antibiotic susceptibility and incidence of late-onset Klebsiella pneumoniae neonatal sepsis over a six-year period in a neonatal intensive care unit in Karachi, Pakistan. Int J Infect Dis 2013;17(11):e961-5.

20. Khattab et al. Ventilator-associated pneumonia in NICU. Menoufia Med J 2014;27:73-77.

21. N Afzali, et al. Pneumothorax after Mechanical Ventilation in Newborns; Iran J Pediatr Mar 2011; 21 (No 1), Pp: 45-50.

22. Kermorvant-Duchemin E, Laborie S, Rabilloud M, Lapillonne A, Claris O. Outcome and prognostic factors in neonates with septic shock. Pediatr Crit Care Med 2008; 9(2):186-91. 